\title{
Regime de Metas Inflacionárias: os Impactos sobre o Desempenho Econômico dos Países
}

\author{
- ROBERTA LOBODA BIONDI*
}

- RUDINEI TONETO JR. **

\begin{abstract}
RESUMO
O objetivo deste artigo é analisar empiricamente os impactos da adoção do sistema de metas inflacionárias para a inflação e crescimento real do produto, diferenciando os impactos entre países desenvolvidos (PD) e em desenvolvimento (PED). Foram coletados dados de inflação e crescimento do PIB para 5 I países entre 1995 e 2004, utilizando o grupo de países que adotam metas inflacionárias como o grupo de tratamento e os que não adotam como grupo de controle. Aplicou-se metodologia apropriada a painel de dados. Os resultados mostram que entre os $P E D$, aqueles que adotam o regime apresentam inflação 3,8 pontos percentuais abaixo da média dos que não adotam, e taxa de crescimento real do PIB 0,8 ponto percentual abaixo da média do grupo de controle. Para o caso dos PD, os resultados são inversos, porém de menor magnitude ( $I, 2$ e $0, I$ ponto percentual, respectivamente). Isto sinaliza que, para os PED, a queda no crescimento do produto estaria relacionada à maior dificuldade enfrentada pelos mesmos na cons-trução de credibilidade, obrigando-os a seguir políticas restritivas e um desenho rígido para o regime.
\end{abstract}

\section{Palavras-Chave}

metas de inflação, dados em painel, painel dinâmico, países desenvolvidos, países em desenvolvimento

\section{ABSTRACT}

The main goal of this paper is to analyze empirically the effect of the adoption of the inflation targeting to both the inflation rate and the economic growth, allowing for different impacts for developed and developing countries. We collected data on inflation and economic growth rates for 5 I countries between 1995 and 2004, classifying the countries adopting inflation targeting as the treatment group and the remaining set of countries as the control group. The methodology adopted was a panel data model. The results we get indicate that for developing countries those adopting inflation targeting present inflation rate $3.8 \%$ below the average of those not adopting the regime, and economic growth rate $0.8 \%$ below the average of the control group. For the developed countries, the results are the opposite but in lower magnitude $(1.2 \%$ and $0.1 \%$, respectively). One possible explanation is that for the PED the decrease in the output growth may be related to the difficulty they face in building their credibility, since they have to commit to more restrictive policies and a strict design for the regime.

\section{KEYWORDS}

inflation targeting, panel data, dynamic panel, developed countries, developing countries

\author{
JEL CLASSIFICATION \\ C23, E3I, E52, E6I
}

\footnotetext{
+ Este artigo é resultante da dissertação de Mestrado apresentada ao Departamento de Economia da FEA-RP/USP e teve apoio financeiro da FAPESP. Os autores agradecem as valiosas sugestões, críticas e comentários dos pareceristas anônimos da revista Estudos Econômicos. Os erros remanescentes são de inteira responsabilidade dos autores.

* Banco Itaú S.A. Endereço para contato: Av. Engenheiro Armando de Arruda Pereira, 707 - Piso 0 - Torre Eudoro Villela - CEP: 04344-902 - São Paulo - SP. E-mail: rlobodabiondi@gmail.com.

* Professor Titular do Departamento de Economia da FEA-RP/USP. Endereço para contato: Av. do Bandeirantes, 3900 - CEP: 14049-900 - Ribeirão Preto - SP. E-mail: rtoneto@usp.br.

(Recebido em abril de 2007. Aceito para publicação em abril de 2008).
} 


\section{INTRODUÇÃO}

A proposta deste trabalho é avaliar os impactos da adoção do regime de metas de inflação para o desempenho econômico dos países em termos da taxa média de inflação e crescimento real do produto utilizando metodologia aplicada a painel de dados.

A partir dos anos 90, o regime de metas de inflação tem sido adotado em vários países desenvolvidos e em desenvolvimento desde sua adoção pioneira na Nova Zelândia (1990), seguida por Canadá e Chile (1991), Reino Unido (1992) e Suécia (1993).

Desde 1999, o Brasil baseia sua política macroeconômica no tripé considerado o mais consistente por acadêmicos, policy makers e organismos institucionais: câmbio flutuante, equilíbrio fiscal e metas de inflação. Alega-se que a primeira peça do tripé seja necessária para garantir o ajustamento do balanço de pagamentos, a segunda, para controlar a demanda agregada e evitar amplas flutuaçôes cambiais, além de permitir a liberação da taxa de juros para fins de controle inflacionário, e a terceira é utilizada como a âncora (referência) nominal do sistema.

A necessidade da utilização de âncoras nominais está ligada ao desejo dos países de manter a inflação baixa dado o elevado custo de transação nas decisões, e à possibilidade de instabilidade econômica em um contexto de ampla variabilidade de preços.

Nesse sentido, destacou-se como alternativa de política monetária o regime de metas de inflação, que pode ser definido como uma estratégia de política monetária que parte do reconhecimento explícito de que o objetivo primordial é a estabilidade de preços. Esse objetivo é confirmado pelo anúncio oficial de metas quantitativas para a taxa de inflação, e o Banco Central tem flexibilidade para escolher a melhor combinação de instrumentos de política monetária para assim atingi-la. Estas decisões são anunciadas e explicitadas ao público, com o objetivo de aumentar a transparência da política monetária (MISHKIN, 2000).

Existem outros tipos de âncoras nominais como a âncora cambial e as metas de agregados monetários. A primeira foi utilizada por países emergentes, como Brasil e Argentina, após o processo de desinflação de suas economias, mas esta estratégia logo demonstrou suas desvantagens e limitações. A segunda opção tornou-se frágil e irreal diante das inovações financeiras nos últimos anos, impossibilitando a definição de uma meta crível para agregados monetários. Uma terceira alternativa para a perseguição de baixa inflação seria seguir uma política semelhante à do FED (Banco Central dos Estados Unidos), que não define nenhuma meta rígida de inflação, mas 
demonstra claramente seu objetivo de baixa inflação (GIAMBIAGI; MATHIAS; VELHO, 2006).

Portanto, dentre as outras possibilidades de âncoras nominais, o regime de metas de inflação tornou-se uma boa alternativa para os países. Após a adoção desse sistema, na maior parte dos países foram verificadas reduções na taxa de inflação e sua posterior manutenção. Entretanto, esse fato parece ser verificado também entre os demais países que não adotaram o sistema, isto é, a estabilização da inflação parece ter sido uma questão que se verificou em quase todos os países do mundo, independente do tipo de política monetária utilizada. Uma questão importante é saber se os países que adotaram o sistema de metas conseguiram manter a estabilidade com menores sacrifícios em termos de crescimento real do produto.

Na literatura empírica atual não há consenso exato em relação ao melhor ou pior desempenho, em termos de inflação e crescimento do produto, dos países após a adoção do sistema. Os resultados encontrados divergem de acordo com a metodologia, o período e a seleção de países utilizados.

Dessa forma, o objetivo deste trabalho é inserir nesse debate a utilização de um painel de dados para avaliar empiricamente quais os impactos da adoção do sistema de metas inflacionárias sobre a taxa de inflação e crescimento real do produto dos países. Foram utilizadas técnicas aplicadas a painel de dados em uma especificação dinâmica para a inflação e outra em nível para o crescimento do PIB. Para isso, selecionou-se uma amostra de 51 países, entre eles desenvolvidos e em desenvolvimento, uma abordagem ainda não vista nos estudos empíricos recentes.

Os resultados econométricos encontrados apontam certo benefício da adoção do sistema de metas de inflação para o caso dos países em desenvolvimento (PED), pois estes experimentam reduções significativas em suas médias de inflação relativamente aos países desse mesmo grupo que não adotam. Entretanto, existe um custo em termos de crescimento real do PIB, pois os PED que adotam o sistema tendem a apresentar média de crescimento inferior aos que não adotam. Para os países desenvolvidos (PD), os que adotam o sistema apresentam taxa de inflação e crescimento real do PIB pouco maiores dos que não adotam.

O artigo está dividido em cinco seções. Após esta introdução, faz-se uma revisão dos artigos empíricos relevantes que tratam da avaliação do regime. Posteriormente, será apresentada a metodologia utilizada, assim como as estatísticas descritivas dos dados utilizados. A quarta seção traz os resultados para as especificações de inflação e de crescimento real do PIB. Na última seção, seguem as principais conclusões do traba- 
lho. No Apêndice A está a lista de países selecionados para este estudo e o Apêndice $\mathrm{B}$ traz as considerações teóricas sobre os métodos de estimação utilizados.

\section{LITERATURA EMPÍRICA SOBRE OS IMPACTOS DA ADOÇÃO DO SIS- TEMA DE METAS DE INFLAÇÃO}

Alguns trabalhos empíricos sobre esse tema são categóricos em afirmar que o regime de metas de inflação contribui para um melhor desempenho em termos de produto e inflação nos países que passam a adotar o regime. Svensson (1997) defende que o regime de metas de inflação gera benefícios sobre as economias por resolver o problema da inconsistência intertemporal, fonte do viés inflacionário. Além disso, o regime reduz a variabilidade da inflação e, quando implementado com certa flexibilidade em relação à convergência das taxas de inflação para a meta, o regime também pode gerar benefícios sobre o produto, reduzindo a sua variabilidade.

Entretanto, um estudo realizado por Ball e Sheridan (2005) questiona se a adoção oficial do regime de metas de inflação melhora o desempenho econômico dos países em termos de inflação e crescimento do produto. ${ }^{1}$ Os autores chegaram à conclusão de que após controlar para o estado inicial dessas variáveis, não é encontrada nenhuma diferença significativa no desempenho econômico entre os grupos de países que adotaram o regime de metas de inflação e os que não adotaram.

No referido trabalho, os autores compararam o desempenho de sete países de economia desenvolvida da OECD que adotaram oficialmente o regime nos anos 90 (países "targeters") com 13 países também desenvolvidos que nunca adotaram (referenciados como países "non-targeters"). ${ }^{2}$ Para avaliar se a adoção do sistema de metas de inflação produz impacto efetivo sobre as variáveis macroeconômicas de interesse, eles utilizaram a metodologia de "diferenças em diferenças", o que requer a definição de uma data de corte que distingue o período pré-metas (anterior à adoção do sistema de metas de inflação pelos países) do período pós-metas. A data de corte escolhida pelos autores foi o terceiro trimestre de 1993, que corresponde à média das datas efetivas de adoção do regime nos países "targeters".

Para todos os países da amostra os autores calcularam as respectivas médias e volatilidades das variáveis de interesse (inflação e crescimento real do PIB) no período pré e pós-metas de forma que o banco de dados dos autores era composto por 20

1 Os autores consideraram a média e volatilidade das taxas de inflação, crescimento real do PIB e taxa de juros.

2 Países considerados "targeters" por Ball e Sheridan (2005): Austrália, Canadá, Finlândia, Espanha, Suécia, Reino Unido e Nova Zelândia. Países considerados "non-targeters": Estados Unidos, Japão, Dinamarca, Áustria, Bélgica, França, Alemanha, Irlanda, Itália, Holanda, Portugal, Noruega e Suíça. 
observações, uma para cada país. Eles realizaram estimações por "diferenças em diferenças" separadamente para cada uma das variáveis macroeconômicas e utilizaram como controle o estado inicial das mesmas, além da dummy que informa se o país adota ou não o sistema de metas. A inclusão do estado inicial das variáveis, ou seja, a média no período pré-metas, deve-se à tentativa de controlar um possível processo de reversão das médias dessas variáveis nos países.

Os resultados encontrados por Ball e Sheridan (2005) apontam para o fato de que os países que adotam o regime de metas inflacionárias demonstraram um desempenho melhor do que os países que não adotam em termos de queda nas taxas médias de inflação. Entretanto, esse resultado decorre do fato de que as economias dos países que adotaram o regime de metas inflacionárias na década de 90 experimentaram um desempenho pior do que os outros países no período anterior. Uma vez controlado isso na regressão (estado inicial), não existem evidências de que o regime de metas inflacionárias melhora o desempenho dos países em termos de média e volatilidade da taxa de inflação e crescimento real do produto.

Destacam-se, aqui, algumas limitações para os resultados encontrados por Ball e Sheridan (2005). Tais autores incluíram na análise somente países desenvolvidos que adotaram o regime de metas de inflação na década passada. Portanto, considerar prazos mais longos para a avaliação dos impactos do regime, e utilizar uma amostra maior de países, o que traria maior variabilidade aos dados, poderia alterar os resultados encontrados. Além disso, a estimação conta somente com 20 observações, o que poderia levar a erros como a maior probabilidade de se aceitar a hipótese nula quando esta é falsa. Outra crítica aos autores é a definição da data de corte do período pré e pós-adoção, que pode ser caracterizada como uma definição subjetiva, podendo assim alterar a significância dos parâmetros estimados.

Um trabalho realizado por Thomas Y. Wu (2004) também tinha como objetivo principal identificar os impactos da adoção do regime de metas de inflação para o desempenho econômico dos países. Para isso, o autor coletou dados de taxas de inflação trimestrais desde o primeiro trimestre de 1985 até o terceiro de 2002 para 22 países da OECD. Dois resultados interessantes foram encontrados pelo autor, e são opostos aos encontrados por Ball e Sheridan (2005). O primeiro evidencia que os PD que adotaram o regime de metas de inflação experimentaram uma queda em suas taxas médias de inflação e tal resultado não era devido somente a um processo de reversão das médias.

O segundo resultado encontrado por Wu mostra que não foi possível encontrar evidências de que os países que passaram a adotar o regime de metas de inflação apresentaram aumento significativo em suas taxas reais de juros após a adoção do 
regime de metas. Mesmo controlando pelo nível da taxa de juros real praticada nesses países, ainda era observada uma significativa relação entre a adoção do regime de metas e a queda da taxa de inflação. Em outras palavras, os resultados encontrados pelo autor rejeitam a hipótese de que o melhor desempenho das taxas de inflação nos países que adotam o regime de metas inflacionárias é decorrente de uma política monetária mais agressiva com a prática de manutenção de elevadas taxas de juros reais. Dessa forma, tais resultados corroboram a idéia de que a adoção do regime de metas de inflação aumenta a credibilidade das autoridades monetárias dos países e informa aos agentes econômicos a preferência da sociedade por baixas taxas de inflação, fazendo com que esta se mantenha em níveis baixos sem a necessidade da ação de uma política monetária muito mais rígida.

O estudo desenvolvido por Wu (2004) também fez referência ao caso dos $\underline{\text { PD }}$ para mostrar a eficácia do regime de metas de inflação. Atualmente, ainda não é conhecido um estudo comparativo do desempenho econômico entre os países que adotam o regime de metas de inflação relativamente aos que não adotam, considerando também o caso dos PED. É importante ressaltar que a seleção somente de PD para a amostra é passível de uma crítica relevante devido à quase ausência de diferenças entre as características econômicas dos países selecionados, ou seja, todos os países são muito parecidos, o que diminui a variabilidade dos dados e pode comprometer a veracidade dos resultados encontrados.

Um estudo recente para o caso das economias emergentes foi desenvolvido por Gonçalves e Salles (2008). Os autores utilizaram a mesma metodologia proposta por Ball e Sheridan (2005), mas para uma seleção de 36 países considerados economias emergentes, entre os quais 13 adotaram o regime de metas inflacionárias. $\mathrm{O}$ período da análise foi de 1980 a 2005.

O objetivo desses autores era investigar se as variações na taxa média de inflação e na variabilidade do crescimento do produto foram maiores nos países com metas relativamente aos países sem metas. Os resultados encontrados pelos autores demonstram que os países do primeiro grupo apresentaram maiores quedas tanto na taxa média de inflação quanto na volatilidade do crescimento real do produto quando comparados aos países sem metas. Tal resultado não estaria ligado somente a um processo de reversão das médias. Apesar de as variáveis selecionadas apresentarem um valor maior no período inicial (antes da adoção do regime) no caso dos países que adotaram o regime, após controlar esse fato na estimação, conclui-se que a adoção do regime de metas inflacionárias promove um impacto benéfico para o desempenho 
econômico dos PED incluídos na amostra dos autores por reduzir tanto suas taxas de inflação quanto a volatilidade do produto. ${ }^{3}$

Contudo, destaca-se que não existe um consenso exato na literatura empírica sobre o melhor ou pior desempenho econômico de um país que tenha adotado oficialmente o regime de metas inflacionárias. Os resultados encontrados diferem de acordo com a seleção de países, a metodologia utilizada e o período analisado.

Nesse sentido, o objetivo deste estudo é avaliar quais os impactos efetivos da adoção do sistema de metas de inflação para o desempenho econômico dos países em termos de inflação e crescimento real do produto, a partir de uma amostra que inclua países desenvolvidos e em desenvolvimento. Dado isso, a análise em painel é uma abordagem metodológica interessante, capaz de controlar as heterogeneidades não observadas de cada país e possibilitar uma análise dinâmica das variáveis de interesse com a inclusão de seus valores defasados como variável explicativa nas estimações, superando algumas das limitações das análises em cross-section. A próxima seção apresenta a metodologia utilizada.

\section{METODOLOGLA E DADOS}

A análise dos dados em painel tem por objetivo introduzir uma nova metodologia para se avaliar os impactos da adoção do sistema de metas de inflação para o desempenho econômico dos países em termos de inflação e crescimento do PIB. O tratamento dos dados em painel é dotado de várias vantagens por ser mais informativo, proporcionar estimativas mais eficientes dos parâmetros, permitir o estudo das dinâmicas individuais e controlar as heterogeneidades individuais não observadas dos países.

Para realizar a análise em painel, além dos dados relativos à inflação (medida pelo Índice de Preços ao Consumidor) e ao crescimento real do PIB, foram coletados dados relativos à situação fiscal dos países como dívida total do setor público consolidado (em percentual do PIB) e superávit primário do governo, assim como dados relativos à questão externa como o saldo da conta corrente, da conta financeira, valor das reservas em moeda estrangeira, exportações e importações em relação ao PIB, taxa real de juros e taxa nominal de câmbio (moeda nacional/dólar). ${ }^{4}$

3 Na primeira versão do artigo - Gonçalves e Salles (2005) -, os autores também analisaram os impactos do sistema de metas de inflação no crescimento médio dos países em desenvolvimento (35 países, sendo 10 que adotam metas) e não encontraram evidências de ganhos ou perdas sobre o lado real da economia, medido pela média do PIB.

4 A taxa de juros real foi obtida descontando-se da taxa de juros nominal (taxa money market ou treasury bill rate) a taxa de inflação medida pelo Índice de Preços ao Consumidor. A taxa real de câmbio também 
Todos esses dados foram coletados em freqüência anual entre os anos de 1995 e 2004 para os 51 países incluídos na amostra (o Apêndice A apresenta a lista dos países selecionados). Entre eles, 24 são PED. Os dados foram coletados do Fundo Monetário Internacional na base de dados International Financial Statistics (IFS). ${ }^{5}$ A Tabela 1 traz a lista dos países que adotaram oficialmente o sistema de metas de inflação, assim como a data de adoção, segundo o grau de desenvolvimento dos países.

TABELA I-METAS DE INFLAÇÃO: PAÍSES QUE ADOTARAM

\begin{tabular}{lc}
\hline Países desenvolvidos & Trimestre da adoção \\
\hline Austrália & T4 1994 \\
Canadá & T1 1991 \\
Coréia do Sul & T4 1998 \\
Espanha & T4 1994 - T4 1998 \\
Finlândia & T1 1993 - T4 1998 \\
Islândia & T1 2001 \\
Israel & T1 1992 \\
Nova Zelândia & T3 1990 \\
Noruega & T1 2001 \\
Reino Unido & T1 1993 \\
Suécia & T1 1995 \\
Suíça & T1 2000 \\
\hline Países em desenvolvimento & Trimestre da adoção \\
\hline África do Sul & T1 2000 \\
Brasil & T3 1999 \\
Chile & T1 1991 \\
Colômbia & T1 1999 \\
Hungria & T3 2001 \\
México & T1 1999 \\
Peru & T1 1994 \\
Polônia & T4 1998 \\
República Tcheca & T1 1998 \\
Tailândia & T2 2000 \\
\hline
\end{tabular}

Fonte: Organização do autor.

foi obtida a partir da taxa de câmbio nominal descontando-se o IPC do país no ano. Utilizou-se na estimação uma versão simplificada da taxa real de câmbio, pois não foi considerada a taxa de inflação do dólar para o seu cálculo.

5 A seleção dos países para a análise em painel foi baseada na disponibilidade de dados durante o período determinado. A classificação dos países segundo seu grau de desenvolvimento foi baseada na classificação do FMI. 
Todos os 22 países que adotaram em algum momento o regime de metas de inflação estão incluídos no banco de dados. Dessa forma, entre toda a amostra, 29 países fazem parte do conjunto dos que nunca adotaram oficialmente o regime de metas de inflação. Espanha e Finlândia deixaram de ter o sistema de metas de inflação como estratégia de política monetária em 1998, quando foi introduzida a moeda única na Área do Euro ${ }^{6}$; entretanto, tais países não foram excluídos da amostra.

O período de 1995 a 2004 foi escolhido devido à melhor operacionalização dos dados, visto que a amostra compreende países que passaram por um período de aceleração inflacionária antes de 1995. Assim, adicionar informações sobre a taxa de inflação antes de 1995 poderia prejudicar os resultados já que os dados poderiam apresentar problemas como presença de raiz unitária, não estacionariedade, entre outros, quando a dimensão temporal da amostra se eleva. A equação a seguir descreve o modelo dinâmico para a inflação:

$\pi_{i t}=c+\beta^{1} \pi_{i t-1}+\beta^{2} M I_{i t}+\beta^{3} p d_{i}+\beta^{4} M I^{*} p d_{i t}+\beta^{5} r_{i t}+\beta^{6} \Delta \varepsilon_{i t}+\beta^{7} s p_{i t}+v_{i t}+\eta_{i}$

$i=1,2$ , $51 ; t=1,2$, 10.

em que:

$\pi_{i t}$ - taxa de inflação medida pelo índice de preços ao consumidor ao ano;

$\pi_{i t-1}$ - taxa de inflação defasada em um período;

$M I_{i t}$ - variável dummy que assume o valor um se o país adota o regime de metas de inflação no tempo $t(t=1,2,3, \ldots, 10)$ e zero caso contrário.

$p d_{i}$ - variável dummy que assume o valor um se o país é desenvolvido e zero caso contrário;

$M I * p d_{i t}$ - denota uma dummy de interação que assume o valor um se o país é desenvolvido e adota o regime de metas no tempo $t$;

$r_{i t}$ - taxa real de juros em $t$;

$\Delta \varepsilon_{i t}$ - variação percentual da taxa real de câmbio entre $t$ e $t$-1;

$s p_{i t}$-superávit primário do governo em percentual do PIB em $t$;

$v_{i t}$ - termo aleatório;

$\eta_{i}$ - efeito específico não-observável de cada país.

6 Países que integram a Área do Euro: Áustria, Bélgica, Finlândia, França, Alemanha, Grécia, Irlanda, Itália, Luxemburgo, Holanda, Portugal e Espanha. 
Assume-se que: $E\left(v_{i t}\right)=0$ e $E\left(v_{i t} \mid X_{i t}\right)=0$ em que $X_{i t}$ é o conjunto de regressores do modelo. Dessa forma, o termo aleatório apresenta média zero e não existe correlação entre o termo aleatório e os regressores.

A equação (l) deve ser tratada como uma decomposição da inflação em suas fontes, ocorrida no período analisado em cada país da amostra, controlando as especificidades de cada um deles, assim como suas características quanto ao desenvolvimento e estratégia de política monetária adotada.

Além da inclusão da taxa de inflação no período anterior como uma possível fonte inflacionária no período $t$, foram consideradas outras variáveis de controle para determinação do nível de inflação. A taxa real de juros foi incorporada ao modelo com o objetivo de se controlar o efeito sobre a inflação de uma possível atuação mais rígida da política monetária nos países após a adoção do regime de metas inflacionárias para se estabilizar os níveis de inflação e atingir a meta estabelecida.

Em um sistema de metas de inflação, as autoridades monetárias utilizam todas as informações disponíveis e a taxa de juros nominal como instrumento para coordenar as expectativas dos agentes quanto à evolução da taxa de inflação. Dessa forma, as autoridades monetárias controlam as taxas de juros nominais, as quais afetam as taxas de juros reais, que, por sua vez, afetam a taxa de inflação (MORAIS; ANDRADE, 2004).

$\mathrm{Na}$ decomposição da inflação em suas causas, também é preciso levar em consideração o canal de transmissão da taxa de câmbio, pois a política monetária também afeta a inflação através desta. Dessa forma, foi incluída a variação da taxa de câmbio na equação (1).

A variável que representa a política fiscal é o saldo primário do governo. Esperase que quanto mais positivo este saldo, menor a taxa de inflação, representando o resultado de uma política fiscal restritiva. Uma das atribuições dos países antes da adoção oficial do sistema de metas de inflação é adquirir credibilidade para a atuação da política monetária, e uma das formas dos países cumprirem tal pré-requisito é controlar as contas do governo e apresentar sucessivos superávits fiscais primários. Dessa forma, os países demonstram que a única preocupação de suas autoridades será efetivamente a política monetária, ou seja, não haverá a contaminação desta por questões fiscais. Tal imposição leva os policy makers à perseguição de uma política fiscal restritiva para dar credibilidade aos objetivos da política monetária, o que poderia influenciar indiretamente o comportamento das taxas de inflação, impactando-as 
negativamente. Por isso, é importante incluir no modelo de decomposição da taxa de inflação alguma variável fiscal como controle.

A especificação dinâmica da inflação é semelhante ao modelo utilizado por Wu (2004). Nosso objetivo com tal especificação é avaliar a significância estatística e econômica do parâmetro $\beta^{2}$, ou seja, conhecer qual o impacto efetivo da adoção do sistema de metas para as taxas médias de inflação dos países controlando as condições iniciais dessa variável, assim como as políticas de juros, cambial e fiscal atuantes nos países.

As condições iniciais da inflação nos países estão representadas pela introdução da variável $\pi_{i t-l}$ do lado direito da equação; essa variável representa um controle ao possível processo de reversão à média da taxa de inflação dos países. Se o parâmetro $\beta^{l}$ associado à primeira defasagem da taxa de inflação mostrar-se significativo, e positivo entre 0 e 1 , isso indicará que a taxa de inflação dos países segue um processo auto-regressivo estacionário.

Intuitivamente, a equação (1) sinaliza que a taxa de inflação apresenta certo grau de persistência ou inércia. Na presença de persistência ou inércia, países que apresentam taxas de inflação inicial mais elevadas tendem a apresentar maiores reduções em suas taxas de inflação posteriormente (WU, 2004). Para demonstrar isso, subtrai-se $\pi_{i t-1}$ de ambos os lados da equação (1), obtendo-se:

$$
\Delta \pi_{i t}=c+\left(\beta^{1}-1\right) \pi_{i t-1}+\beta^{2} M I_{i t}+\beta^{3} p d_{i}+\beta^{4} M I^{*} p d_{i t}+\beta^{5} r_{i t}+\beta^{6} \Delta \varepsilon_{i t}+\beta^{7} s p_{i t}+v_{i t}+\eta_{i}
$$

Se $\beta^{l}$ possuir um valor entre 0 e 1 , então $\left(\beta^{l}-1\right)$ estará entre -l e 0 , assim, quanto maior a taxa de inflação em um determinado ano, maior será a redução da taxa de inflação do país no ano seguinte. Se os países que adotam metas de inflação experimentarem maior redução das taxas de inflação somente porque apresentam taxas de inflação relativamente mais elevadas no período inicial da amostra (segunda metade dos anos 90), então espera-se que $\beta^{l}$ seja estatisticamente significante e $\beta^{2}$ seja nãosignificante. Será interessante observar a significância estatística e econômica do coeficiente da dummy de adoção das metas de inflação após o controle das condições iniciais.

A estimação dessa especificação foi realizada pelo Método Generalizado dos Momentos desenvolvido por Arellano e Bover (1995); Blundell e Bond (1998), com erros padrões corrigidos (conhecido na literatura como system GMM). Esse método é uma extensão do método original desenvolvido por Arellano e Bond (1991) (referenciado como difference GMM), o qual corrige o problema de endogeneidade 
criado pela inclusão de variáveis dependentes defasadas como regressores, tratando o modelo como um sistema de equaçóes, com uma equação para cada momento do tempo. Essas equações diferem somente no conjunto de instrumentos que são utilizados, os quais são as próprias defasagens da variável predeterminada em nível.

Segundo Arellano e Bover (1995) e Blundell e Bond (1998), existe um problema com o estimador difference GMM original, pois as variáveis defasadas em nível freqüentemente são fracos instrumentos da variável explicativa em primeiras diferenças (endógena). Em outras palavras, na prática, geralmente há pouca correlação entre as primeiras diferenças e os níveis defasados dessas variáveis, pois geralmente elas são muito persistentes no tempo, o que aproxima suas diferenças de um passeio aleatório. Nesse cenário, a utilização de instrumentos fracos pode influenciar o desempenho do estimador (GMM) em grandes e pequenas amostras. Assintoticamente, a variância dos coeficientes estimados aumenta, e, em pequenas amostras, a utilização de instrumentos pobres pode viesar os coeficientes.

Para o caso da taxa inflação, é razoável admitir certa persistência em suas séries ${ }^{7}$, as quais serão utilizadas como instrumento no estimador difference GMM. É sabido que quanto maior a persistência das séries, menor a correlação entre os seus níveis e as subseqüientes diferenças defasadas. Assim, para o caso da especificação dinâmica da inflação, possivelmente os instrumentos do difference GMM serão fracos, trazendo problemas para as propriedades deste estimador, justificando o uso do system GMM.

Para reduzir esse potencial problema com o viés e a imprecisão associados com o estimador difference GMM usual, foi utilizada para a estimação do painel dinâmico uma metodologia proposta pelos autores referenciados anteriormente que combina um sistema de regressões em diferenças com uma regressão em nível (conhecido como estimador system GMM). Apesar desta metodologia de estimação estar sendo cada vez mais difundida e utilizada, esse desenvolvimento é recente e justifica uma explicação pouco mais detalhada que se encontra no Apêndice B deste artigo.

Para testar se os instrumentos utilizados na estimação pelo difference GMM realmente são fracos, além da estimação da equação (I) pelo system GMM, será realizado

7 Realizamos um exercício de estimar o processo univariado AR(l) para conhecer o coeficiente autoregressivo da inflação para todos os países da amostra entre 1995 e 2004. Assim, para cada país rodamos um processo AR(1) considerando o seguinte modelo: $\pi_{i t}=(\alpha-1) \pi_{i t-1}+v_{i t}$ e conhecemos uma estimativa de $\alpha$. Alega-se que quanto maior a persistência de $\alpha$, menor a correlação entre as primeiras diferenças da inflação em nível e os instrumentos, ou seja, os regressores defasados em nível $\left(\pi_{\mathrm{t}-1}\right.$ defasados). A média encontrada desse coeficiente entre todos os países da amostra foi de 0,50 . Para o caso dos 28 PD da amostra, a média foi de 0,43 e para os 23 PED, a média desse coeficiente foi 0,58 , o que caracteriza a inflação por um elevado grau de persistência. Os resultados não serão reportados integralmente devido a limitações de espaço, mas poderão ser disponibilizados a pedidos. 
um teste de robustez dos resultados e dos instrumentos utilizados a partir de comparaçóes entre as estimativas dos parâmetros de interesse pelo difference GMM, pelo estimador de efeitos fixos, e por mínimos quadrados ordinários (MQO pooled). Esse teste de robustez baseia-se no método proposto por Bobba e Coviello (2006) que comparam o desempenho do estimador system GMM com estimadores alternativos que têm propriedades conhecidas nas aplicações em painel dinâmico para testar a existência de ganhos em termos de precisão das estimativas.

Ademais, será possível justificar a utilização do system $G M M$ para a estimação da especificação dinâmica da inflação, o que implica a inclusão da condição de momento adicional, $E\left[\left(\pi_{i t-s}-\pi_{i, t-s-1}\right)\left(\eta_{i}+v_{i t-1}\right)\right]=0$ (para $s=1$ ), ou seja, as variaçóes na taxa de inflação devem ser ortogonais ao efeito fixo dos países da amostra (ver Apêndice B).

Como o objetivo deste artigo é avaliar os impactos da adoção do sistema de metas de inflação também para o crescimento real do produto dos países, o segundo modelo estimado é descrito por:

$y_{i t}=\alpha+\delta^{1} M I_{i t}+\delta^{2} p d_{i}+\delta^{3} M I_{i t} * p d_{i t}+\delta^{4} r_{i t}+\delta^{5} \Delta \varepsilon_{i t}+\delta^{6} s p_{i t}+\delta^{7} M I_{i t} * r_{i t}+\eta_{i}+v_{i t}$

$i=1, \ldots, 51 ; \mathrm{t}=1, \ldots 10$.

em que: ${ }^{8}$

$y_{i t}$ - crescimento real do produto em $t$;

$M I^{*} r_{i t}$ - variável iterada: dummy de metas e taxa de juros real em $t$.

A variável iterada $\mathrm{MI}^{*} \mathrm{r}_{\text {it }}$ foi incluída no modelo com o objetivo de detectar qual a sensibilidade do produto a políticas monetárias restritivas quando os países adotam o sistema de metas de inflação. Se o coeficiente dessa variável se mostrar significante e positivo, significa que sob as diretrizes do regime de metas de inflação é possível encontrar a mesma taxa de inflação com uma política monetária menos rígida, ou seja, o efeito da atuação das políticas monetárias sobre o produto é menos recessivo para os países que adotam o sistema de metas de inflação.

Esse resultado seria esperado dada a maior credibilidade atingida pelas autoridades monetárias que se comprometem efetivamente a manter as taxas de inflação estáveis. Espera-se que as políticas se tornem mais críveis e diminuam o sacrifício da sociedade em termos de menor crescimento do produto quando o objetivo é manter as

8 As outras variáveis explicativas da equação (2) seguem as mesmas definições das variáveis da especificação dinâmica da inflação. 
taxas de inflação baixas e estáveis. Assim, o trade-off de curto prazo entre inflação e crescimento tenderia a ser menos pronunciado para os países que adotam o sistema de metas de inflação.

A especificação do produto (equação 2) faz alusão à dinâmica da curva IS em uma economia aberta. A taxa real de juros é o canal pelo qual a taxa de juros nominal afeta a taxa de inflação, ou seja, uma elevação na taxa de juros nominal eleva a taxa de juros real, que, por sua vez, afeta a demanda agregada reduzindo a taxa de inflação.

Com a estimação do modelo de crescimento espera-se encontrar qual o impacto da adoção do regime de metas de inflação para o crescimento do produto dos países, controlando o seu nível de desenvolvimento, a atuação das políticas monetária e fiscal, e as variações nas taxas reais de câmbio. ${ }^{9}$ Na próxima seção, serão apresentadas as estatísticas descritivas e os resultados das estimações dos modelos de inflação e crescimento real do PIB.

\section{RESULTADOS}

Antes de apresentar os resultados das estimações para o painel, é interessante comentar algumas das estatísticas descritivas. O Gráfico 1 apresenta as taxas médias de inflação medidas pelo índice de preços ao consumidor no mundo, nos PD e nos PED.

De acordo com o Gráfico l, é possível observar que as taxas médias de inflação em todo o mundo vêm seguindo uma trajetória de queda e, mais do que isso, assumiram um comportamento estável nos últimos anos.

9 Inicialmente, foram realizadas várias simulações de regressões para se testar a melhor especificação para o modelo de crescimento. Outras variáveis macroeconômicas foram incluídas no modelo, como: grau de abertura da economia; saldo da conta corrente e conta financeira sobre o produto; relação entre reservas em moeda estrangeira e importações; e o montante da dívida pública total em percentual do produto. Entretanto, nenhuma delas se mostrou significativa para a modelagem do crescimento do produto; assim, elas foram excluídas do modelo. 


\section{GRÁFICO I - TAXAS MÉDIAS DE INFLAÇÃO (\% AO ANO): MUNDO, PAÍSES DESENVOLVIDOS E PAÍSES EM DESENVOLVIMENTO. PERÍODO: $1995-2004$}

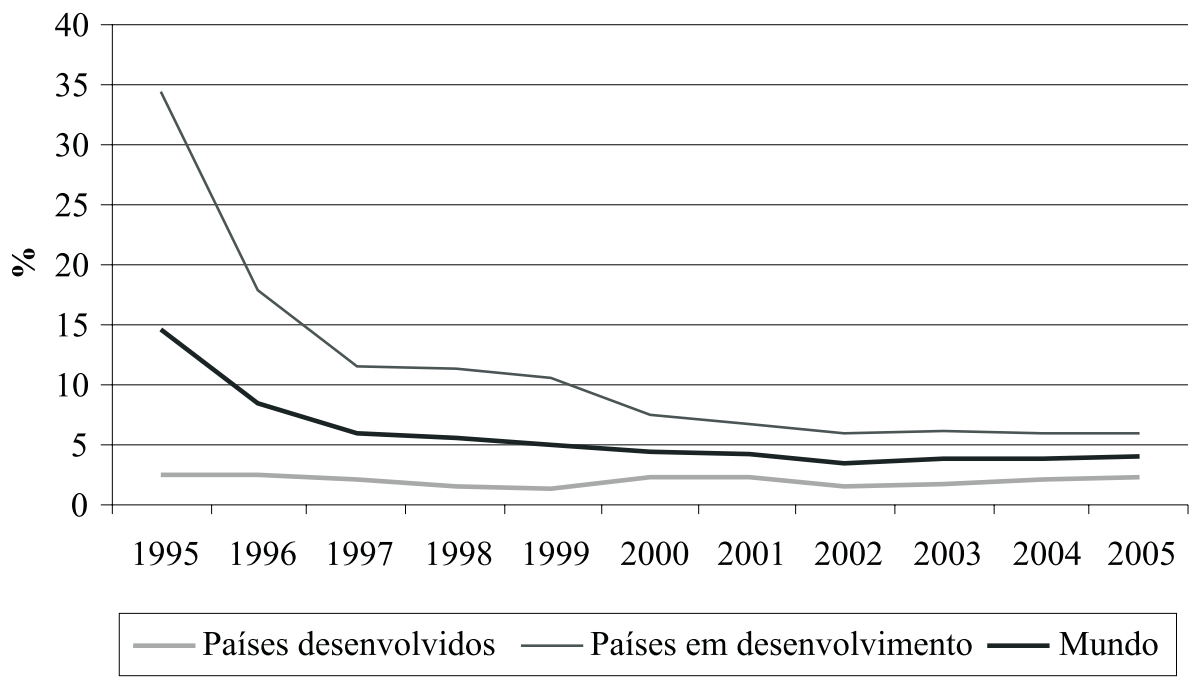

Fonte: Organização do autor com dados do FMI (IFS).

Nota: O gráfico foi construído com os dados de todos os países do mundo, e não restrito apenas aos países considerados neste artigo.

Podemos perceber que, independente do nível de desenvolvimento e da estratégia de política monetária utilizada, todos os países do mundo prezam pela manutenção de baixas taxas de inflação e vêm se engajando em políticas que garantam a estabilidade inflacionária. Atualmente, a taxa média de inflação em todo o mundo é de $3,9 \%$ ao ano, enquanto nos países desenvolvidos essa taxa é de $2,2 \%$, e nos países em desenvolvimento essa taxa alcança o valor de 5,9\%.

Considerando a amostra de 51 países, é interessante observar se existe diferencial de média de inflação e crescimento do PIB entre os países que adotam o regime de metas e os que não adotam. A tabela a seguir apresenta as médias de inflação e crescimento para os países com e sem metas segundo o grau de desenvolvimento. 
TABELA 2 - MÉDIAS DA TAXA DE INFLAÇÃO E CRESCIMENTO REAL DO PIB (\%AA) - PERÍODO: 1995 A 2004

\begin{tabular}{lcccccc}
\hline & \multicolumn{2}{c}{ Países desenvolvidos } & & \multicolumn{2}{c}{ Países em desenvolvimento } \\
\cline { 2 - 3 } \cline { 5 - 6 } & \multicolumn{2}{c}{ com metas } & sem metas & & com metas & sem metas \\
\hline Taxa de inflação & 2,5 & 2,1 & & 5,6 & 16,3 \\
Crescimento real do PIB & 3,2 & 3,2 & & 3,3 & 3,5 \\
\hline
\end{tabular}

Fonte: Dados FMI, organização do autor.

De acordo com a Tabela 2, observa-se que para o grupo dos $\mathrm{PD}$, os que não adotam o regime de metas inflacionárias apresentam uma taxa média de inflação menor do que os que adotam, embora não-significativa. Já no caso dos PED, verifica-se uma diferença significativa entre os dois grupos. ${ }^{10}$

A inexistência de diferencial significativo entre as taxas médias de inflação dos PD com e sem metas pode ser explicada pelo fato de estes apresentarem características inerentes ao elevado desenvolvimento, como elevada credibilidade das autoridades monetárias, histórico de baixas taxas de inflação, aspectos culturais, além de outras características macroeconômicas que garantem que qualquer tipo de política monetária que almeje a estabilidade de preços obtenha sucesso.

Em relação ao crescimento real do PIB, de acordo com o resultado do teste de igualdade de médias, tanto para os PD como para os PED, não é possível rejeitar a hipótese nula de que a diferença das médias de crescimento do produto entre os países com e sem metas é zero. ${ }^{11}$

A Tabela 3 apresenta os resultados das estimações da especificação dinâmica da inflação (equação l) por diferentes estimadores. Conforme discutido na seção anterior, teoricamente se alega-se que a estimativa mais precisa dos parâmetros deve ser resultante do system GMM; entretanto, é interessante testar a validade dos instrumentos empregados por tal estimador. Uma forma simples e válida de se fazer isso é realizar comparações entre as suas estimativas e as de outros estimadores com propriedades conhecidas. $^{12}$

10 Realizamos o Teste $t$ de igualdade de médias: Ho: média inflação (não adota) - média inflação (adota) $=0$.

Países desenvolvidos: $t=-1,32$ e Prob $>|\mathrm{t}|=0,200$ (não é possível rejeitar a hipótese nula).

Países em desenvolvimento: $t=5,55$ e Prob $>|t|=0,000$ (rejeita-se a hipótese nula).

11 Teste $t$ de igualdade de médias: Ho: média crescimento (não adota) - média crescimento (adota) $=0$. Países desenvolvidos: $t=0,0615$ e Prob $>|t|=0,95$ (não é possível rejeitar a hipótese nula).

Países em desenvolvimento: $t=0,43$ e Prob $>|t|=0,67$ (não é possível rejeitar a hipótese nula).

12 Esse método é conhecido na literatura como "Bounding Procedure", aplicado por Bobba e Coviello (2006). 


\section{TABELA 3 - COEFICIENTES ESTIMADOS EQUAÇÃO (I) - VARIÁVEL DE- PENDENTE: TAXA DE INFLAÇÃO (\% AO ANO) - PERÍODO 1995- 2004}

\begin{tabular}{|c|c|c|c|c|c|c|}
\hline & $\begin{array}{c}\text { Efeito Fixo } \\
\text { (Within) }\end{array}$ & $\begin{array}{c}\text { MQO } \\
\text { (pooled) }\end{array}$ & $\begin{array}{l}\text { dif GMM } \\
\text { (one-step) }\end{array}$ & $\begin{array}{r}\text { dif GMM } \\
\text { (two-step) }\end{array}$ & $\begin{array}{l}\text { system GMM } \\
\text { (one-step) }\end{array}$ & $\begin{array}{c}\text { system GMM } \\
\text { (two-step) }\end{array}$ \\
\hline Inflaçãa $_{(t-1)}$ & $\begin{array}{c}0.119^{\star \star \star} \\
{[0.040]}\end{array}$ & $\begin{array}{l}0.225^{\star *} \\
{[0.088]}\end{array}$ & $\begin{array}{c}0.064^{\star \star \star} \\
{[0.023]}\end{array}$ & $\begin{array}{c}0.064^{\star \star *} \\
{[0.001]}\end{array}$ & $\begin{array}{l}0.152^{\star} \\
{[0.093]}\end{array}$ & $\begin{array}{c}0.152^{*} \\
{[0.094]}\end{array}$ \\
\hline Juros real $r_{i t}$ & $\begin{array}{l}-0.456^{\star \star} \\
{[0.180]}\end{array}$ & $\begin{array}{l}-0.259^{* *} \\
{[0.131]}\end{array}$ & $\begin{array}{l}-0.530^{\star \star \star} \\
{[0.046]}\end{array}$ & $\begin{array}{l}-0.528^{\star \star *} \\
{[0.005]}\end{array}$ & $\begin{array}{l}-0.297^{*} \\
{[0.160]}\end{array}$ & $\begin{array}{l}-0.289^{*} \\
{[0.165]}\end{array}$ \\
\hline$\Delta \varepsilon_{i t}$ & $\begin{array}{l}0.202^{* \star *} \\
{[0.030]}\end{array}$ & $\begin{array}{l}0.242^{* * *} \\
{[0.042]}\end{array}$ & $\begin{array}{l}0.221^{\star * *} \\
{[0.017]}\end{array}$ & $\begin{array}{l}0.221^{* \star *} \\
{[0.001]}\end{array}$ & $\begin{array}{l}0.288^{\star \star *} \\
{[0.056]}\end{array}$ & $\begin{array}{l}0.291^{*} \\
{[0.054]}\end{array}$ \\
\hline $\mathrm{sp}_{\text {it }}$ & $\begin{array}{l}-0.147 \\
{[0.160]}\end{array}$ & $\begin{array}{l}-0.173 \\
{[0.114]}\end{array}$ & $\begin{array}{l}-0.323^{* * *} \\
{[0.123]}\end{array}$ & $\begin{array}{l}-0.320^{* * *} \\
{[0.006]}\end{array}$ & $\begin{array}{l}-0.190 \\
{[0.369]}\end{array}$ & $\begin{array}{l}-0.156 \\
{[0.372]}\end{array}$ \\
\hline Metas $_{\text {it }}$ & $\begin{array}{l}-2.665^{\star *} \\
{[1.147]}\end{array}$ & $\begin{array}{l}-2.194^{\star *} \\
{[0.901]}\end{array}$ & $\begin{array}{l}-3.051^{*} \\
{[1.793]}\end{array}$ & $\begin{array}{c}-2.883^{\star \star *} \\
{[0.302]}\end{array}$ & $\begin{array}{l}-3.747^{\star *} \\
{[1.658]}\end{array}$ & $\begin{array}{l}-3.780^{\star *} \\
{[1.658]}\end{array}$ \\
\hline$P D_{\text {it }}$ & - & $\begin{array}{l}-5.173^{* * *} \\
{[1.430]}\end{array}$ & - & $\begin{array}{l}- \\
-\end{array}$ & $\begin{array}{c}-6.576^{* \star *} \\
{[1.787]}\end{array}$ & $\begin{array}{c}-6.689^{* * *} \\
{[1.880]}\end{array}$ \\
\hline Metas ${ }^{*} D_{\text {it }}$ & $\begin{array}{l}3.756^{\star * *} \\
{[1.269]}\end{array}$ & $\begin{array}{c}3.145 \\
{[1.062]}\end{array}$ & $\begin{array}{c}3.801 \\
{[2.855]}\end{array}$ & $\begin{array}{l}3.759^{\star * *} \\
{[0.962]}\end{array}$ & $\begin{array}{l}5.958^{\star * *} \\
{[2.206]}\end{array}$ & $\begin{array}{l}4.971^{* *} \\
{[2.081]}\end{array}$ \\
\hline $\begin{array}{l}\text { Constante } \\
\text { Dummy ano }\end{array}$ & $\begin{array}{c}5.253^{* * *} \\
{[0.934]} \\
\text { sim }\end{array}$ & $\begin{array}{c}6.062^{* * *} \\
{[1.772]} \\
\operatorname{sim}\end{array}$ & $\begin{array}{c}-0.542^{* * *} \\
{[0.188]} \\
\operatorname{sim}\end{array}$ & $\begin{array}{c}-0.538^{* * *} \\
{[0.026]} \\
\operatorname{sim}\end{array}$ & $\begin{array}{l}7.119^{* * *} \\
{[2.168]} \\
\operatorname{sim}\end{array}$ & $\begin{array}{l}7.224^{* * *} \\
{[2.300]} \\
\operatorname{sim}\end{array}$ \\
\hline $\begin{array}{l}\text { Hansen (Sargan } \\
\text { para dif-GMM) }\end{array}$ & - & - & 0.00 & 0.744 & 1.00 & 1.00 \\
\hline Dif-Hansen & - & - & - & - & 1.00 & 1.00 \\
\hline $\mathrm{AR}(1)$ & - & - & 0.000 & 0.1031 & 0.108 & 0.099 \\
\hline $\operatorname{AR}(2)$ & - & - & 0.107 & 0.2393 & 0.193 & 0.176 \\
\hline observações & 403 & 403 & 350 & 350 & 403 & 403 \\
\hline $\mathrm{N}$ & 51 & 51 & 50 & 50 & 51 & 51 \\
\hline
\end{tabular}

Notas: Os erros padrão robustos estão entre ( ) e os símbolos $*^{* * *, * * *}$ denotam que o coeficiente individual é significante em $10 \%, 5 \%$ e $1 \%$, respectivamente. As estimativas do System GMM em dois estágios contam com as variâncias corrigidas de acordo com Windmeijer (2005). Os p-values dos testes de Hansen e Sargan estão reportados e a Ho refere-se à validade dos instrumentos utilizados. O DifHansen testa a validade da inclusão da terceira equação de momento requerida pelo system GMM. Os valores reportados em $\mathrm{AR}(\mathrm{l})$ e $\mathrm{AR}(2)$ são os p-values dos testes de autocorrelação dos erros em primeira e segunda ordem, respectivamente. Foram incluídas dummies de ano como controle em todas as estimaçôes.

Ao analisar os parâmetros estimados do coeficiente auto-regressivo da inflação, observa-se que os estimadores de Efeito Fixos (Within) e de MQO (pooled) correspondem respectivamente, ao menor e maior valor entre todas as estimativas $(0,12 \mathrm{e}$ 0,22). A partir do parâmetro resultante do difference GMM em um e dois estágios é possível identificar o forte viés para baixo de suas estimativas, as quais são inferiores ao estimador Within. 
Paralelamente, os valores dos coeficientes estimados da inflação defasada pelo system GMM, em um e dois estágios, ficam dentro da banda inferior e superior dada pelos dois primeiros estimadores reportados na tabela. O teste Dif-Hansen referese à validade da inclusão da condição de momento adicional requerida pelo system $G M M$, e estatística chi-quadrado desse teste não rejeita a hipótese nula de validade de tal condição. Mais uma evidência da persistência da inflação dos países ao longo do tempo, validando o uso de tal estimador no modelo de especificação dinâmico da inflação.

Como visto, o estimador system GMM utiliza as condições de momentos para estimar os parâmetros, consistente e eficientemente, de acordo com duas variaçóes: one-step e two-step. O estimador em dois estágios é assintoticamente mais eficiente que o estimador do primeiro estágio, mas os erros-padrão resultantes podem ser intensamente enviesados para baixo (ARELLANO; BOND, 1991); (BLUNDELL; BOND, 1998), trazendo imprecisão na inferência, principalmente em casos de amostras finitas e com grande número de instrumentos.

Contudo, para a estimação do painel dinâmico da inflação pelo estimador System $G M M$ de dois estágios, utilizou-se um método para a aplicação de um corretor na matriz de variâncias e co-variâncias para tratar a heterocedasticidade e resultar em estimativas corrigidas dos erros padrão em amostras finitas. Esse método foi derivado por Windmeijer (2005) e garante que, após a correção da matriz, as estimativas em dois estágios sejam mais eficientes que as estimativas em um estágio mesmo para amostras finitas. ${ }^{13}$

Em todas as estimações pelo GMM foram utilizadas, além das defasagens da variável dependente em primeiras diferenças e em nível, variáveis adicionais para compor a matriz de instrumentos. São elas: dummy informando se o país é desenvolvido, a própria dummy de metas de inflação, dummy de ano e dummy de continente, informando a qual continente o país pertence (variáveis estritamente exógenas que covariam com os regressores). O valor do p-value $(0,95)$ do teste Dif-Hansen aponta para a validade desses instrumentos adicionais, assim como o p-value do teste de Sargan, para o caso do difference GMM, segue no mesmo sentido.

Sabe-se que a confiabilidade desses testes pode ser enfraquecida caso o número de instrumentos seja elevado. Entretanto, realizamos outras simulações reduzindo o número de instrumentos, e não foram encontradas diferenças expressivas entre as novas estimativas e as reportadas na Tabela 3; por isso, optou-se por considerar e

13 Para maiores detalhes técnicos sobre a eficiência dos estimadores em um e dois estágios, assim como das propostas de tratamento para o problema do viés do estimador em dois estágios, como realizadas por Beck e Levine (2004), consultar o Apêndice B deste artigo. 
interpretar os resultados do estimador mais eficiente e não viesado, o system GMM em dois estágios.

Antes de interpretar as implicações econômicas, é interessante observar a robustez dos resultados e a significância do coeficiente da dummy de 'metas' em todas as estimações. Em todas elas a dummy de adoção do sistema de metas de inflação mostrouse significativa e com impacto negativo na média de inflação observada nos países em desenvolvimento da amostra.

Considerando os resultados apontados pelo system GMM (two-step), o coeficiente da taxa de inflação defasada, também referenciada como condição inicial, mostrou-se significativo e positivo. Esse coeficiente possui valor entre zero e um $(0,15)$, indicando que em geral, a taxa de inflação dos países da amostra segue um processo de reversão às médias. Além disso, existe certo grau de persistência ou inércia nas taxas de inflação, de forma que $15 \%$ da variação absoluta da taxa de inflação entre $t$ e $t$-1 é levado para a taxa de inflação em $t$.

Observando o sinal e a significância do coeficiente estimado da dummy de adoção das metas $\left(\mathrm{MI}_{\mathrm{it}}\right)$, podemos afirmar que mesmo controlando o fato de a inflação dos países estar seguindo um processo de reversão à média, os países que adotam o sistema de metas de inflação apresentam taxas médias de inflação inferiores àqueles que não adotam. Contudo, é importante diferenciar o efeito da adoção do regime de metas de inflação para o grupo dos PD e dos PED.

Para o caso dos PD, o diferencial da taxa de inflação anual entre países que adotam o regime de metas e os que não adotam é o somatório de dois coeficientes: o coeficiente da dummy de adoção somado ao coeficiente da variável iterada $M{ }^{*}{ }^{*} D_{i t}$. Assim, os PD que adotam o regime de metas inflacionárias experimentam taxas de inflação $1,19(-3,78+4,97)$ ponto percentual acima da taxa média de inflação dos PD que não adotam.

Além disso, caso um PD adote o sistema de metas, ele apresentará uma taxa de inflação de 1,73 (-6,69 + 4,97) ponto percentual abaixo da dos PED. Caso o PD não adote o sistema de metas de inflação, ele apresentará uma taxa média de inflação de 6,7 pontos percentuais abaixo da dos PED.

Para os PED, os resultados apontam que aqueles que adotam o regime de metas têm taxas médias de inflação 3,8 pontos percentuais abaixo dos países que não adotam. Portanto, pode-se dizer que, em tais países, a redução da taxa de inflação dos que adotam o sistema de metas de inflação não ocorre somente devido a um processo de 
reversão às médias. Ademais, é importante chamar atenção para o valor expressivo do coeficiente pontual da dummy de metas para os PED.

Observando os outros coeficientes estimados para as variáveis de controle, verificase que, diferentemente dos outros controles, o superávit primário não se mostrou significativo, o que nos permite afirmar que a elevação de um ponto percentual da taxa real de juros reduz a taxa de inflação em 0,29 ponto percentual, assim como uma desvalorização cambial impacta positivamente a taxa de inflação também em 0,29 ponto percentual.

O efeito líquido de uma desvalorização real do câmbio e da elevação da taxa real de juros é nulo caso as variações sejam iguais, ou seja, uma elevação da taxa de juros real é capaz de anular o efeito de uma desvalorização cambial sobre a inflação, caso ela exista e as duas variações sejam de igual magnitude. Assim, após uma desvalorização real do câmbio, as variações necessárias na taxa real de juros deverão ser iguais ou maiores que as variações cambiais para que a política monetária afete negativamente as taxas de inflação.

Em relação ao modelo da taxa de crescimento real do produto, a Tabela 4 apresenta os resultados da estimação da equação (2). Para essa especificação também foi incluída como variável de controle uma dummy para cada ano. A estimação foi realizada pelo método de Mínimos Quadrados Generalizados Factíveis já que a estrutura dos erros dos dados apresentava heterocedasticidade e autocorrelação serial. ${ }^{14} \mathrm{O}$ teste de especificação de Hausman foi realizado para verificar se as heterogeneidades não observadas dos países da amostra estariam correlacionadas com os regressores. $\mathrm{O}$ resultado da estatística do teste, assim como seu p-value foram, respectivamente, 8,58 e 0,74 , ou seja, $E\left(\eta_{i} \mid x_{i t}\right)=0$; os efeitos individuais dos países não estão correlacionados com o conjunto de regressores do modelo. Dessa forma, o estimador de efeitos aleatórios é eficiente e consistente, o que permite a estimação do modelo por MQGF.

14 Teste de Heterocedasticidade (Teste LR): Ho: $\operatorname{sigma}(\mathrm{i})^{2}=\operatorname{sigma}^{2}$ para todo $i(i=1,2, \ldots 5 \mathrm{l})$. Estatística: $\chi^{2}(49)=221,29$; P-value $=0,000$.

Teste de autocorrelação $\mathrm{AR}(\mathrm{l})$ (Wooldridge): Ho: não-autocorrelação de primeira ordem. Estatística: $\mathrm{F}(1,47)=11,28 ; \mathrm{P}$-value $=0,002$. 
TABELA 4 - COEFICIENTES ESTIMADOS (MQGF): EQUAÇÃO (2) VARIÁVEL DEPENDENTE: TAXA DE CRESCIMENTO REAL DO PIB (\% AO ANO) PERÍODO: 1995 - 2004

\begin{tabular}{lccc}
\hline & Coeficientes & $\begin{array}{c}\text { Erros padrão } \\
\text { robustos }\end{array}$ & $\mathrm{p}$-value \\
\hline Juros_real $\mathrm{r}_{\text {it }}$ & -0.07 & 0.02 & 0.004 \\
$\Delta \varepsilon_{i t}$ & -0.08 & 0.01 & 0.000 \\
$\Delta \varepsilon_{i t-1}$ & 0.03 & 0.01 & 0.003 \\
$\mathrm{sp}_{\text {it }}$ & 0.10 & 0.03 & 0.002 \\
MI $_{\text {it }}$ & -0.81 & 0.47 & 0.087 \\
MI*pd $_{\text {it }}$ & 0.89 & 0.46 & 0.056 \\
pd $_{\text {it }}$ & -1.68 & 0.31 & 0.000 \\
MI*r $_{\text {it }}$ & 0.02 & 0.05 & 0.741 \\
d__1997 $_{\text {d_1998 }}$ & 2.32 & 0.33 & 0.000 \\
d_1999 $_{\text {d_2000 }}$ & 0.98 & 0.33 & 0.003 \\
d_2004 $_{\text {constante }}$ & 1.03 & 0.32 & 0.001 \\
\hline Wald chi2(13) & 2.57 & 0.33 & 0.000 \\
Log likelihood $=-758.5057$ & Prob $>$ chi2 $=0.0000$ & 0.000 \\
\hline
\end{tabular}

A partir do resultado da estimação da equação (2), podemos afirmar que a taxa real de juros impacta negativamente o crescimento real do produto por afetar também negativamente a demanda agregada.

Com relação à variação da taxa real de câmbio, observa-se que o coeficiente dessa variável em nível possui o sinal contrário ao esperado, pois uma variação maior significaria uma desvalorização do câmbio real que geraria efeitos positivos sobre as exportações líquidas e sobre o produto da economia. Entretanto, o coeficiente da variação da taxa de câmbio real é negativo e significativo, ou seja, uma variação maior da taxa de câmbio afetaria o crescimento do PIB negativamente. Com o intuito de explicar esse resultado, foi incluída a primeira defasagem da variação da taxa de câmbio real. O coeficiente estimado dessa variável mostrou-se significativo e positivo, ou seja, uma desvalorização do câmbio real gera impacto positivo sobre as exportações líquidas e sobre o produto da economia após um ano.

Esse resultado sinaliza que uma desvalorização cambial pode estar relacionada a movimentos de capitais estrangeiros, podendo ser vista como uma medida de risco do país; assim, oscilações da taxa de câmbio poderiam ser vistas como reflexo de uma incerteza maior afetando a atividade econômica negativamente no curto prazo. 
Após uma defasagem, a desvalorização cambial traria benefícios para as exportações líquidas e para o crescimento do produto.

O coeficiente do superávit primário mostrou-se significativo e positivo, ou seja, um maior superávit primário fiscal traz benefícios para o crescimento real do PIB dos países. Dessa forma, podemos interpretar os elevados níveis de superávits como uma medida de "saúde fiscal" do país, o que pode trazer benefícios em termos de crescimento do PIB.

O coeficiente da variável iterada $\mathrm{MI}^{*} \mathrm{r}_{\mathrm{it}}$, apesar de apresentar o sinal esperado, não se mostrou significativo. $\mathrm{O}$ resultado esperado seria um coeficiente positivo, pois teoricamente para os países que adotam o regime de metas inflacionárias, o impacto recessivo da política monetária deveria ser menos pronunciado devido aos ganhos de credibilidade na condução da política monetária após a adoção do regime em questão.

A dummy $p d_{i t}$ capta o diferencial da taxa de crescimento do produto entre os PD e os PED; entretanto, esse diferencial altera-se caso o país adote o sistema de metas de inflação. Caso um país desenvolvido não adote o sistema de metas, seu diferencial de crescimento em relação aos PED é de -1,68. Já para o caso dos países desenvolvidos que adotam metas, esse diferencial é menor, $-0,8(-1,68+0,89)$. Assim, PD tendem a crescer menos relativamente aos PED (de acordo com a hipótese da convergência); no entanto, o diferencial diminui para o caso dos PD que adotam o sistema de metas de inflação.

Em relação aos efeitos do regime de metas para o crescimento, entre os $\mathbf{P D}$, o diferencial da taxa de crescimento entre os países que adotam e os que não adotam o sistema de metas é o somatório dos coeficientes das variáveis $\mathrm{MI}_{\mathrm{it}}$ e $\mathrm{MI}^{*} \mathrm{pd}_{\mathrm{it}}$. Assim, os PD que adotam metas de inflação apresentam uma taxa de crescimento do produto de $0,10(-0,81+0,89)$ ponto percentual acima dos países desse mesmo grupo que não adotam, ou seja, uma diferença inexpressiva. Já entre os PED, o efeito da adoção do regime de metas inflacionárias para o crescimento dos países é de -0,81 ponto percentual.

Analisando os resultados estimados de inflação e crescimento conjuntamente, observamos que o efeito da adoção das metas de inflação para os países desenvolvidos é contrário ao efeito da adoção para os países em desenvolvimento.

Para o primeiro grupo, os países que adotam metas inflacionárias apresentam taxas de inflação um ponto percentual mais elevadas relativamente aos países que não adotam. 
Esse resultado pode ser explicado pelo fato de todos os PD apresentarem atualmente taxas médias de inflação abaixo de $3 \%$ ao ano, e, dentro desse grupo, os países que não adotam metas, como Estados Unidos, Japão, Alemanha e França, têm médias de inflação historicamente mais baixas que as de todos os outros PD. Assim, o patamar de comparação para a taxa de inflação é muito baixo, fazendo com que o resultado da adoção do sistema de metas nesses países seja a manutenção das taxas baixas e estáveis, mas relativamente pouco maior do que a média de inflação do grupo de PD que não adotam o regime.

Além disso, para tais países a adoção do sistema de metas parece não prejudicar o crescimento real do produto relativamente àqueles que não adotam metas. Esse resultado pode estar relacionado ao fato de os países desenvolvidos, em geral, já contarem com certa credibilidade em relação à condução da política monetária e à manutenção de baixas taxas de inflação. Assim, a construção de credibilidade por meio de uma política de juros bastante restritiva não se faz necessária.

Para o grupo dos PED, a adoção do sistema de metas de inflação leva a uma redução nas taxas de inflação, e esse resultado não se deve somente a um processo de reversão à média. Contudo, em relação ao crescimento do produto, os PED que adotam o regime apresentam médias de crescimento real do PIB pouco menor relativamente aos que não adotam.

Defende-se aqui que tal resultado poderia estar ligado a questóes relativas à credibilidade da condução da política monetária, pois esses países realizam políticas econômicas restritivas com o intuito de ganhar credibilidade e alcançar a eficiência prevista em teoria pelo regime de metas inflacionárias. Tais políticas restritivas podem afetar negativamente o produto da economia, fazendo com que os possíveis efeitos benéficos do regime de metas de inflação sobre o crescimento real da economia demorem mais a ser percebidos.

A partir dos resultados encontrados é possível afirmar que o desempenho econômico, em termos de média de inflação e crescimento real do PIB, parece ser afetado pelo sistema de metas de inflação principalmente nos PED. Os efeitos para os PD são praticamente irrelevantes, já que estes apresentam estabilidade inflacionária e quase nenhuma diferença no produto comparando o grupo dos países que adotam e os que não adotam metas.

Não parece ser surpreendente a dificuldade de se identificar importantes ganhos em termos de inflação e produto para os países desenvolvidos que adotam sistema de metas inflacionárias, já que, em geral, o grupo de PD não enfrenta graves problemas macroeconômicos ou severos processos inflacionários. Já para o grupo dos PED, 
os impactos sobre o desempenho econômico, das diferentes estratégias de política monetária utilizadas, parecem ser mais nítidos e expressivos.

Esses resultados encontram sustentação na literatura empírica recente. Ball e Sheridan (2005) em seu mais recente artigo mostram, a partir de um exercício empírico com 20 países desenvolvidos, que a adoção do sistema de metas de inflação não provoca benefícios e nem malefícios à performance econômica dos mesmos, pois as quedas na média e volatilidade inflacionária são explicadas apenas por um processo de reversão às médias, tanto nos países que adotam como nos que não adotam tal regime. Em relação ao produto, os autores também não identificaram efeito robusto e/ou significativo relacionado ao sistema de metas. Apesar da utilização de metodologias bastante distintas, as conclusões do presente artigo seguem nesse mesmo sentido, demonstrando a irrelevância do sistema de metas inflacionárias para explicar diferenças no desempenho econômico dos PD.

Também é possível observar semelhança entre os resultados encontrados aqui e as conclusões de Gonçalves e Salles (2008), que aplicaram a mesma metodologia de Ball e Sheridan (2005) para um grupo de 36 países em desenvolvimento e comprovaram empiricamente que países que adotam o sistema de metas experimentaram maiores quedas nas taxas de inflação relativamente àqueles sem metas.

\section{CONCLUSÃO}

Entre as estratégias de política monetária existentes, o regime de metas de inflação apresenta-se como o de maior apelo na atualidade. Grande parte dos países desenvolvidos e em desenvolvimento tem adotado essa estratégia com o objetivo de aliar estabilidade de preços ao crescimento do produto e do emprego. Atualmente, em torno de 20 países adotam o sistema de metas de inflação.

Neste artigo avaliaram-se quais os impactos dessa estratégia de política monetária para o desempenho econômico dos países em termos de inflação e crescimento do produto.

De acordo com a análise em painel, os resultados demonstram que o sistema de metas de inflação traz impactos significativos para as taxas de inflação e crescimento real do produto dos países, especialmente para o caso dos países em desenvolvimento.

Entre os países desenvolvidos, os que adotam o sistema de metas de inflação apresentam taxas de inflação e de crescimento do produto um pouco maiores relativamente 
aos países desenvolvidos que não adotam o sistema. Embora haja um pequeno efeito da adoção desse sistema para as variáveis econômicas dos países desenvolvidos, essa hipótese parece não ser muito relevante para a evolução da taxa de inflação dos mesmos, pois historicamente as taxas de inflação desses países são baixas e estáveis.

Para o caso dos países em desenvolvimento, a adoção do sistema de metas de inflação é eficaz em reduzir as taxas médias de inflação dos países. Entretanto, a adoção parece provocar efeitos negativos sobre o crescimento do produto real da economia.

Países em desenvolvimento como o Brasil enfrentam maiores custos pela manutenção do sistema de metas de inflação relativamente aos países desenvolvidos, pois os primeiros tendem a enfrentar maiores dificuldades na construção da credibilidade requerida pelo regime. Para elevar a credibilidade, as autoridades monetárias tendem a seguir políticas monetárias restritivas e a ditar um desenho rígido para o regime de metas.

Portanto, o sistema de metas de inflação é uma opção interessante para os países em desenvolvimento com o objetivo de ancorar as expectativas dos agentes e controlar a inflação em níveis baixos.

Em relação ao crescimento econômico, não existe razão teórica trivial para que o sistema de metas influencie de forma direta e positiva o lado real da economia. Entretanto, Mishkin (2000) destaca que alguns países (como a Nova Zelândia) que passaram períodos de desinflação após a adoção do sistema de metas, também experimentaram forte crescimento do produto no período subseqüente. Dessa forma, é possível que além da estabilidade inflacionária, o sistema de metas gere benefícios para o lado real da economia. De acordo com os resultados encontrados neste artigo, no caso dos países em desenvolvimento os possíveis efeitos benéficos gerados pela adoção do sistema para o crescimento do produto ainda não foram detectados empiricamente.

\section{REFERÊNCIAS}

ARELLANO, M.; BOND, S. Some tests of specification for panel data: Monte Carlo evidence and an application to employment equations. London, Review of Economic Studies, 58, p. 277 -297, 1991.

ARELLANO, M.; BOVER, O. Another look at the instrumental-variable estimation of error-components models. Journal of Econometrics, 68, p.29-52, 1995. 
BALL, L.; SHERIDAN, N. Does inflation targeting matter? In: BERNANKE, B.S.; WOODFORD, M. (Eds.). The Inflation-Targeting Debate. University of Chicago Press, 2005.

. Does inflation targeting matter? NBER Working Paper 9577, Cambridge, 2003.

BECK, T.; LEVINE, R. Stock markets, banks, and growth: panel evidence. Journal of Banking and Finance, v. 28, 2004.

BLUNDELL, R., BOND, S. Initial conditions and moment restrictions in dynamic panel data models. Journal of Econometrics, 87, p. 115-143, 1998.

BOBBA, M.; COVIELLO D. Weak instruments and weak identification in estimating the effects of education on democracy. $I A D B$ Working Paper n.569, 2006.

CALDERON, C.; CHONG, A.; LOAYZA, N. Determinants of current account deficits in developing countries. World Bank Research Policy, 2000 (Working Paper n.2398).

GIAMBIAGI, F; MATHIAS, A.; VELHO, E. O aperfeiçoamento do regime de metas de inflação no Brasil. Rio de Janeiro: Instituto de Pesquisa Econômica Aplicada, 2006 (Texto para discussão, n. 1183).

GONÇALVES, C. E. S.; SALLES J. M. Inflation Targeting in emerging economies: what do the data say? Journal of Development Economics, v. 85, p. 312-318, 2008.

. Inflation Targeting in emerging economies: what do the data say? Artigo apresentado no Programa de Seminários Acadêmicos da IPE - USP - São Paulo, 2005. Disponível em: http://www.econ.fea.usp.br/seminarios/ Acesso em: 25 ago 2005.

MISHKIN, F. S. Inflation Targeting in emerging-market countries. The American Economic Review. v. 9, n. 2, p. 105-109, 2000.

MORAIS, J. F. M.; ANDRADE, J. P. Como a divida pública afeta a política monetária ótima? Brasília: ESAF, 42 p. Monografia premiada em $3^{\circ}$ lugar no IX Prêmio Tesouro Nacional - 2004, Ajuste Fiscal e Dívida Pública, Brasília (DF), 2004.

PIRES, M. C. C. Meta ótima para a inflação em um contexto de dívida pública elevada. Brasília: Instituto de Pesquisa Econômica Aplicada, 2006 (Texto para discussão, n. 1152).

SVENSSON, L. E. O. Inflation forecast targeting: implementing and monitoring inflation targets. European Economic Review, 41, p. 1111-1146, 1997.

WINDMEIJER, F. A finite sample correction for the variance of linear efficient twostep GMM estimators. Journal of Econometrics, 126, p. 25- 51, 2005.

WU, T. Y. Does inflation targeting reduce inflation? An analysis for the OECD industrial countries. Brasília: Banco Central do Brasil, 2004 (Working Paper Series n. 83). Disponível em: http://www.bcb.gov.br/publicações. Acesso em: 20 jan. 2005. 
APENNDICE A

\begin{tabular}{|c|c|c|c|c|c|}
\hline \multicolumn{3}{|c|}{ PAÍSES SELECIONADOS } & \multicolumn{3}{|c|}{ PAÍSES SELECIONADOS } \\
\hline & $\begin{array}{c}\text { País } \\
\text { Desenvolvido? }\end{array}$ & $\begin{array}{l}\text { Adota metas de } \\
\text { inflação? }\end{array}$ & & $\begin{array}{c}\text { País } \\
\text { Desenvolvido? }\end{array}$ & $\begin{array}{l}\text { Adota metas de } \\
\text { inflação? }\end{array}$ \\
\hline & $\operatorname{sim}=1 ;$ não $=0$ & $\operatorname{sim}=1 ;$ não $=0$ & & $\operatorname{sim}=1 ;$ não $=0$ & $\operatorname{sim}=1 ;$ não $=0$ \\
\hline 1 África do Sul & 0 & 1 & 27 Índia & 0 & 0 \\
\hline 2 Alemanha & 1 & 0 & 28 Indonésia & 0 & 0 \\
\hline 3 Argentina & 0 & 0 & 29 Irlanda & 1 & 0 \\
\hline 4 Austrália & 1 & 1 & 30 Islândia & 1 & 1 \\
\hline 5 Áustria & 1 & 0 & 31 Israel & 1 & 1 \\
\hline 6 Bélgica & 1 & 0 & 32 Itália & 1 & 0 \\
\hline 7 Brasil & 0 & 1 & 33 Japão & 1 & 0 \\
\hline 8 Canadá & 1 & 1 & 34 Lituânia & 0 & 0 \\
\hline 9 Chile & 0 & 1 & 35 Luxemburgo & 1 & 0 \\
\hline 10 Chipre & 1 & 0 & 36 Malásia & 0 & 0 \\
\hline 11 Cingapura & 1 & 0 & 37 Marrocos & 0 & 0 \\
\hline 12 Colômbia & 0 & 1 & 38 México & 0 & 1 \\
\hline 13 Coréia do Sul & 1 & 1 & 39 Noruega & 1 & 1 \\
\hline 14 Costa Rica & 0 & 0 & 40 Nova Zelândia & 1 & 1 \\
\hline 15 Croácia & 0 & 0 & 41 Peru & 0 & 1 \\
\hline 16 Dinamarca & 1 & 0 & 42 Polônia & 0 & 1 \\
\hline 17 Equador & 0 & 0 & 43 Portugal & 1 & 0 \\
\hline 18 Espanha & 1 & $0^{*}$ & 44 Reino Unido & 1 & 1 \\
\hline 19 Estados Unidos & 1 & 0 & 45 República Tcheca & 0 & 1 \\
\hline 20 Filipinas & 0 & 0 & 46 Rússia & 0 & 0 \\
\hline 21 Finlândia & 1 & $0^{*}$ & 47 Suécia & 1 & 1 \\
\hline 22 França & 1 & 0 & 48 Suíça & 1 & 1 \\
\hline 23 Grécia & 1 & 0 & 49 Tailândia & 0 & 1 \\
\hline 24 Holanda & 1 & 0 & 50 Turquia & 0 & 0 \\
\hline 25 Hong Kong & 1 & 0 & 51 Uruguai & 0 & 0 \\
\hline 26 Hungria & 0 & 1 & & & \\
\hline
\end{tabular}

\section{APENNDICE B}

As estimações de painel dinâmico propostas por Arellano e Bond (1991) e Arellano e Bover (1995)/Blundell-Bond (1998) são designadas para tratar de diversas questões: estimativas que contam com poucas unidades temporais e muitas observações individuais; existência de variável dependente defasada como regressor; variáveis independentes não estritamente exógenas, ou seja, correlacionadas com realizações passadas e correntes do termo de erro; heterogeneidades individuais não observadas e invariantes no tempo; e presença de heterocedasticidade e autocorrelação nas unidades individuais. Neste apêndice, será abordada a evolução dos métodos de estimação propostos para tratarem dos referidos temas. 
Considere o seguinte modelo dinâmico, onde temos observações de vários países ao longo do tempo ( $i$ : unidade individual; $t$ : unidade temporal):

$$
y_{i t}=\alpha y_{i t-1}+\beta^{\prime} x_{i t}+\eta_{i}+v_{i t}
$$

Claramente, $y_{i t-1}\left(=\alpha y_{i t-2}+\eta_{i}+v_{i t-1}\right)$ é correlacionado com $\eta_{\mathrm{i}}$. Dessa forma, utilizar o estimador de efeitos fixos ou mínimos quadrados resultará em estimativas viesadas. Para eliminar os efeitos fixos dos países, utiliza-se o operador de primeiras diferenças:

$$
y_{i t}-y_{i t-1}=\alpha\left(y_{i t-1}-y_{i t-2}\right)+\beta^{\prime}\left(x_{i t}-x_{i t-1}\right)+\left(v_{i t}-v_{i t-1}\right)
$$

É necessário o uso de instrumentos para resolver o problema de endogeneidade entre as variáveis explicativas e os efeitos fixos, assim como instrumentos para resolver o problema de correlação, criado por construção entre $\left(y_{i t-1}-y_{i t-2}\right)$ e $\left(v_{i t}-v_{i t-1}\right)$.

Segundo a metodologia do estimador GMM original desenvolvida por Arellano e Bond (1991) (difference GMM), se o termo de erro não é correlacionado serialmente e o conjunto de variáveis explicativas é fracamente exógeno, ou seja, se as variáveis explicativas não são correlacionadas com as realizações futuras do termo de erro, os instrumentos válidos para a estimação da equação (II) são as próprias defasagens da variável explicativa endógena $\mathrm{y}_{\mathrm{t}-1} \mathrm{em}$ nível - pois estes instrumentos devem estar correlacionados com a variável explicativa $\left(y_{t-1}-y_{t-2}\right)$ e não com o erro $\left(v_{t t}-v_{t-1}\right)$. O estimador difference GMM utiliza de maneira ótima as novas informações introduzidas pelas variáveis instrumentais e deve seguir as seguintes condições de ortogonalidade:

$$
\begin{aligned}
& E\left[y_{i t-s}\left(v_{i t}-v_{i t-1}\right)\right]=0 \quad \text { para } \mathrm{s} \geq 2 ; \mathrm{t}=3, \ldots, \mathrm{T} . \\
& E\left[x_{i t-s}\left(v_{i t}-v_{i t-1}\right)\right]=0 \quad \text { para } \mathrm{s} \geq 2 ; \mathrm{t}=3, \ldots, \mathrm{T} .
\end{aligned}
$$

Os instrumentos utilizados devem satisfazer duas condições: (1) devem ser não correlacionados com o termo de erro; (2) devem ser correlacionados com as variáveis explicativas endógenas. Se a primeira condição não for satisfeita, o estimador de variáveis instrumentais GMM será viesado e inconsistente. Entretanto, mesmo se os instrumentos forem não correlacionados com o erro, mas forem fracamente 
correlacionados com as variáveis explicativas endógenas, os coeficientes resultantes serão viesados.

Utilizando as condições de momento descritas em (III) e (IV), Arellano e Bond (1991) propõem um estimador GMM em dois estágios. No primeiro estágio assumese que os erros são independentes e homocedásticos entre os países e ao longo do tempo. No segundo estágio, os resíduos obtidos no primeiro passo são usados se encontrar uma estimativa consistente da matriz de variância e co-variância, relaxando então a hipótese de independência e homocedasticidade (BECK; LEVINE, 2004). Dessa forma, é obtido o estimador de dois estágios que é mais eficiente relativo ao estimador do primeiro estágio.

Segundo Arellano e Bover (1995) e Blundell e Bond (1998), existe um problema com o estimador GMM original, pois as variáveis defasadas em níveis freqüentemente são fracos instrumentos da variável explicativa em primeiras diferenças (endógena). A utilização de instrumentos fracos influencia o desempenho do estimador de primeiras diferenças (GMM) em grandes e pequenas amostras. Em grandes amostras, assintoticamente a variância dos coeficientes estimados aumenta; em pequenas amostras, a utilização de instrumentos pobres pode viesar os coeficientes. A possibilidade de as variáveis defasadas em nível serem fracos instrumentos da equação de regressão em primeiras diferenças está ligada à persistência das variáveis explicativas. Quanto maior a persistência, menor a correlação entre os níveis e as diferenças subseqüentes, ameaçando o cumprimento da condição (2) descrita anteriormente.

Para reduzir o potencial problema com o viés e a imprecisão associados com o estimador difference GMM usual, os referenciados autores sugerem a estimação do painel dinâmico segundo uma metodologia que combina um sistema de regressões em diferenças com uma regressão em nível. Os instrumentos das regressões em diferenças são os mesmos referidos anteriormente (as defasagens da variável explicativa endógena em nível), e os instrumentos da regressão em nível são as defasagens da variável explicativa endógena em diferenças, ou seja, $\left(y_{i t-s}-y_{i t-s-1}\right)$ para $s=1$ será o instrumento da regressão em nível. ${ }^{15}$

Para isso, duas adicionais condições de momento devem ser seguidas:

$$
E\left[\left(y_{i t-s}-y_{i, t-s-1}\right)\left(\eta_{i}+v_{i t-1}\right)\right]=0 \quad \text { para } \mathrm{s}=1
$$

15 Para as regressões em nível, somente as diferenças defasadas mais recentes são utilizadas como instrumentos, já que nas regressões em diferenças as defasagens em nível são os instrumentos. Usar outras diferenças defasadas como instrumento resultará em condições de momentos redundantes (ver ARELLANO; BOVER, 1995). 


$$
E\left[\left(x_{i t-s}-x_{i, t-s-1}\right)\left(\eta_{i}+v_{i t-1}\right)\right]=0 \quad \text { para } \mathrm{s}=1
$$

Dessa forma, utilizam-se essas duas condições de momento e emprega-se o estimador system GMM para se obter estimativas consistentes e eficientes para os parâmetros.

Ambos os estimadores difference e system GMM podem apresentar problemas quando aplicados em amostras com um pequeno número de unidades cross-section (ARELLANO; BOND, 1991), (BLUNDELL; BOND, 1998). Nesse caso, os erros padrão assintóticos do estimador em dois estágios são viesados para baixo, e como destacado anteriormente, o estimador em um estágio é assintoticamente ineficiente mesmo sob hemocedasticidade dos erros.

Beck e Levine (2004) defendem que enquanto o estimador em dois estágios é assintoticamente mais eficiente, a inferência assintótica a partir dos erros padrão resultantes do primeiro estágio deve ser mais realista. Ademais, os autores salientam que esse problema deve ser agravado quando o número de instrumentos é maior ou igual ao número de unidades cross-section. Esses mesmos autores propõem três procedimentos para tratar esse potencial problema de inferência. Primeiramente eles utilizam o estimador em um estágio para realizar inferências. No segundo, eles incluem um número limitado de variáveis de controle no modelo para reduzir o número de instrumentos e então minimizar o problema de sobreidentificação, além de maximizar a confiança no estimador system GMM em dois estágios. Por fim, outra sugestão seria aplicar cada condição de momento em todos os períodos disponíveis ao invés de cada condição de momento corresponder a um período determinado; tal procedimento reduz o viés do estimador em dois estágios (ver CALDERON et al., 2000).

Windmeijer (2005) realizou um estudo para identificar as causas do viés para baixo do estimador eficiente system GMM em dois estágios, em caso de ser aplicado em pequenas amostras. Sabendo que o cálculo do peso da matriz, a qual é utilizada para o cálculo das estimativas em dois estágios, é baseado em estimativas iniciais consistentes dos parâmetros, o autor demonstrou que a variação extra, decorrente da presença desses parâmetros estimados no peso da matriz, explica em grande parte a diferença entre os desvios-padrão em amostras pequenas e a variância assintótica do estimador system GMM em dois estágios. O autor estima essa diferença e a partir dela é possível corrigir as variâncias estimadas para o caso de amostras finitas. Experimentos de Monte Carlo com painel de dados demonstram que a estimativa corrigida da variância se aproxima bem de variâncias em amostras finitas, conduzindo a inferências mais precisas. 
Dessa forma, garante-se que o estimador system GMM em dois estágios é mais eficiente relativo ao de um estágio, e quando aplicada a correção proposta por Windmeijer (2005) às variâncias, os erros padrão não serão viesados mesmo em amostras pequenas. 